\title{
Computer Assisted Pathway Generation for Atrazine Degradation in Advanced Oxidation Processes
}

\author{
Xiang $\mathrm{Li}^{1}$, Fang Zeng ${ }^{2}$, Ke $\mathrm{Li}^{{ }^{*}}$ \\ ${ }^{1}$ Department of Computer Science, University of Georgia, Athens, GA; ${ }^{2}$ Faculty of Engineering, University of Georgia, Athens, GA. \\ Email: xiangli@uga.edu, fangzeng@uga.edu, "keli@engr.uga.edu
}

Received 2013

\begin{abstract}
A model was developed to generate the complex degradation pathway of contaminants initiated by hydroxyl radical in the advanced oxidation processes. The model abstracts chemical structures into mathematic graphs. The manipulation of the graphs enumerates the reactions among the large number of molecules, radicals, and other intermediates in the advanced oxidation processes. Using Canonical Simplified Molecular Input Line Entry Specification (Canonical SMILE) representation, the algorithm was able to simulate the reaction of contaminants containing both chain and ring structures. The input chemicals, reaction pattern, and the reaction rules could be specified by users through a graphical user interface. The degradation pathway of Atrazine was used as an example to demonstrate the capability of the algorithm. The generated reaction pathways were compared with those reported in literatures.
\end{abstract}

Keywords: Advanced Oxidation Processes; Modeling; Atrazine; Mechanism Study

\section{Introduction}

Advanced oxidation processes (AOPs) have been widely applied for destroying organic contaminants in water [1]. In AOPs, hydroxyl radical induced chain reactions are the primary mechanisms responsible for the destruction of contaminants. The reaction mechanism normally contains a large number of intermediates and reactions. There has been awareness in the literature that some of the daughter compounds impose more health risks than the parent compounds [2,3]. However, the study of reaction mechanisms may be costly due to the complexity of the chain reaction. In our previous work, a computer assisted model was developed to explore the pathways of byproducts generated by the hydroxyl radical-induced chain reactions in aqueous phase AOPs [4]. In this work, the model is expanded to have the capacity of modeling reaction pathways of contaminants with ring structures. The fundamental methodology is to abstract chemical structure as graph and use graph theory to enumerate elementary steps of complex reactions. According to graph theory, each reactant and reaction mechanism can be modeled as a graph consisting of nodes (as atoms) and edges (as bonds) [5,6]. The addition and elimination of the edges could simulate the reactions.

One of the challenges of using graph theory to abstract chemical structures and reactions is the canonicity of

"Corresponding author. graph representation, i.e. one to one mapping relationship between the chemical and the graph denoting it. Canonical notation eliminates the redundancy of pathway because it provides a way to discern whether a generated reaction or product has already been in the system, regardless of the order of atoms in the structure. There have been various studies on the line notation and canonical modeling of chemicals [7-10], including our previous work of using canonical tree in modeling chemicals containing chain structures [4]. In this work, the Simplified Molecular Input Line Entry Specification (SMILE) and the canonical SMILE algorithm developed by David Weininger were applied for the canonical abstraction of chemicals and reactions rules [10]. By interpreting SMILE string into graph objects and later converts graph back into canonical SMILE string, our work can inherently support ring structured chemicals because SMILE algorithm supports ring structure. The algorithm is able to canonically representing both chain and ring structure and their reactions.

By canonically abstracting chemical structure using graph theory, our model could achieve reaction enumeration and execution based on manipulation of graphs. The details of reaction enumeration through sub-graph matching from reaction pattern table and execution is elaborated hereafter. The algorithm is implemented using Microsoft C\# software package with the Indigo Cheminformatics library [11] to do the molecular structure mod- 
eling and SMILE interpretation.

\section{Modeling Methodology}

\subsection{Model Input and Output: SMILE String Notation)}

The model utilizes canonical SMILE string of reactants as input at the beginning of reaction chain. The canonical SMILE algorithm could guarantee in generating a unique SMILES notation for a given chemical structure, solving the problem of arbitrary notation with equally valid forms [7-10], while at the same time the canonical SMILE could generate different notation for molecular isomers based on their chemical structures. Similarly, at each reaction stage, the intermediate chemicals produced will also be analyzed using the canonical algorithm and transformed into their corresponding canonical SMILE strings, before feeding into the next reaction stage. Therefore, the canonicity is ensured for both the user input reactants and the model simulated products to avoid redundancy. Once each SMILE representation of the chemical is loaded, it will be transformed to its corresponding two dimensional graph form within the model, for the purpose of the subsequent sub-graph pattern matching algorithm. Both the SMILE string form and graph form of the chemical will be used throughout the pathway generation internally, while only SMILE string and its visualization will be displayed as model output.

\subsection{Reaction Enumeration by Sub-Graph Matching}

The model keeps a database consisted of all the reaction rules of the reactions that could happen during an AOP multi-stage reaction. The term "reaction rules" is used here since they are not real reactions, but only the abstraction of reactions derived from literature reports for AOP pathway. There are five major groups of reaction rules, according to the chemical structures of the reactants. The first group, "Hydroxyl Radicals", is consisted of the reactions characterizing the attacking of hydroxyl radicals on molecules. This group could be identified by the existence of the reactant hydroxyl radical ( $\left.\mathrm{HO}^{\circ}\right)$. The second group, "Carbon-Centered Radicals", consists of the reactions characterizing the consequential reactions of the carbon-centered radicals (reactants with $C^{\circ}$ ), which is also the identifier of this group. The third group, "Peroxyl Radicals", characterizes the reactions of the peroxyl radicals (reactants with $\mathrm{C}-\mathrm{O}-\mathrm{O}^{\circ}$ functional group), which are mainly the decaying of the unstable peroxyl radicals. The fourth group, "Oxyl Radicals”, is consisted of the reactions related with $\mathrm{O}^{\circ}$, which is also the identifier of this group. The last group is consisted of the special reactions that could not be summarized into the above four groups. Most of them are reactions that are not involved with radicals but were present in the AOP process. Some other reactions in this group have much faster reaction rate, which gives them higher priority than the reactions in the previous four groups.

All reaction rules are stored in the model as listed in Table 1. The name and the SMILE line notation of the reaction rules are listed under the "Reaction rule name" and "Reaction rule formula" columns respectively in each group. Each reaction was abstracted by the functional groups of the reactants involved, plus any arbitrary group (denoted by " $R$ ”) connecting to them. In order to find potential reactions applicable for the input chemical and intermediate products, the model would iterate through all the reaction rules by using sub-graph pattern matching between the graph of chemical and the graph of reactants defined in the reaction rules. The SMILE string after the reaction name (e.g. "(C-H)" in the first row) denotes the sub-pattern to be matched. In graph theory, a sub-graph of a graph $G$ is defined as having exact same vertices to a subset of $G$ and the corresponding edges. In this work, the atoms are modeled as vertices of the graph and the chemical bonds between the atoms are modeled as edges connecting the vertices. For example, sub-graph matching between the methane $\left(\mathrm{CH}_{4}\right)$ and the pattern "C-H" defined in reaction rule " $\mathrm{H}$-abstraction" will obtain four results: $\left(\mathrm{C}_{1}-\mathrm{H}_{4} ; \mathrm{C}_{1}-\mathrm{H}_{0} ; \mathrm{C}_{1}-\mathrm{H}_{2} ; \mathrm{C}_{1}-\mathrm{H}_{3}\right)$, where the numbers are indices of atoms as shown in the middle of Figure 1. One of the matchings $\left(\mathrm{C}_{1}-\mathrm{H}_{4}\right)$ is highlighted in the right part of the figure. By convention, the carbon atom (C) is omitted in the illustration.

\subsection{Reaction Execution Modeling}

The potential reactions identified from Table 1 would be stored as a list consisting the reaction rule name, the SMILE notation of the participating chemical, and the sub-pattern matching result which is a list consisting the indexes of mapped atoms. The model would then execute the reactions i.e. get the reaction products, by manipulate the bond change or doing modifications on atoms (such as adding radical electron) of reactants for each potential reaction. The exact operation of each reaction rule is predefined by its formula and stored in its corresponding reaction execution table. An example of the reaction rule " $\mathrm{O}_{2}$ addition" is listed in Table 2.

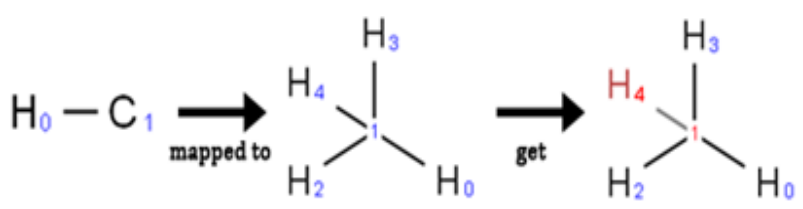

Figure 1. Visualization of sub-graph matching between chemical $\mathrm{CH}_{4}$ (middle) and pattern $\mathrm{C}-\mathrm{H}$ (left). In the mapping result (right), atoms with index 1 and 4 are highlighted as it is matched to the pattern $\mathrm{C}-\mathrm{H}$. 
Table 1. Pattern table for reaction modeling.

\section{Reaction rule name}

\section{Hydroxyl Radicals}

H-abstraction (C-H) [12-14]

Unsaturated bond addition $(\mathrm{R}=\mathrm{R})[15,16]$

\section{Carbon-Centered Radicals}

$\mathrm{O}_{2}$ addition $\left(\mathrm{C}^{*}\right)$ [17]

$\beta$-elimination (C*-O, $\left.\mathrm{C}^{*}-\mathrm{C}-\mathrm{Cl}\right)$ [15]

\section{Peroxyl Radicals ${ }^{\mathrm{a}}$}

Bimolecular decay (C-O-O) [18]

$\mathrm{HO}_{2}^{*} / \mathrm{O}_{2}^{*-}$ elimination (H-O-C-O-O ) [19]

\section{Oxyl Radicals ${ }^{b}$}

$\beta$-scission (C-O*)

1,2-H shift (H-C-O*) [20,21]

\section{Special reactions}

Aldehydes hydrolysis $^{\mathrm{c}}$ (H-C-O) [22,23]

Carbonyl chlorine hydrolysis $(\mathrm{Cl}-\mathrm{C}=\mathrm{O})[18,24]$

hydrolysis of alkyl radicals with $\beta$-halogen ( $\left.\mathrm{C}^{*}-\mathrm{C}-\mathrm{Cl}\right)$ [25]

Hydrolysis of amide $^{\mathrm{d}} \quad(\mathrm{H}-\mathrm{N}-\mathrm{C}=\mathrm{O})$ [26]

Hydrolysis of some small molecules [27]

Dechlorination (H-O-C-Cl, H-O-R-Cl) [18]

Oxidation of glyoxylic acid by $\mathrm{H}_{2} \mathrm{O}_{2}$ [18]

$$
\mathrm{R}_{\mathrm{a}} \mathrm{CH}+\mathrm{HO}^{*} \rightarrow \mathrm{R}_{\mathrm{a}} \mathrm{C}^{*}+\mathrm{H}_{2} \mathrm{O}
$$$$
\mathrm{R}=\mathrm{R}+\mathrm{HO}^{*} \rightarrow \mathrm{R}^{*}-\mathrm{ROH}
$$

$$
\begin{aligned}
& \mathrm{R}_{2} \mathrm{C}^{*}+\mathrm{O}_{2} \rightarrow \mathrm{R}_{2} \mathrm{COO} \\
& \mathrm{R}_{2} \mathrm{C}^{*} \mathrm{OR} \rightarrow \mathrm{R}_{2} \mathrm{CO}+\mathrm{R}^{*} \\
& \mathrm{R}-\mathrm{HCCl}-\mathrm{H}_{2} \mathrm{C}^{*} \rightarrow \mathrm{RCH}=\mathrm{CH}_{2}+\mathrm{Cl}^{*}
\end{aligned}
$$

$$
\begin{aligned}
& \mathrm{R}_{2} \mathrm{CO}^{*} \rightarrow \mathrm{R}_{2} \mathrm{C}=\mathrm{O}+\mathrm{R}^{*} \\
& \mathrm{R}_{2} \mathrm{CHO}^{*} \rightarrow \mathrm{R}_{2} \mathrm{C}^{*} \mathrm{OH}
\end{aligned}
$$

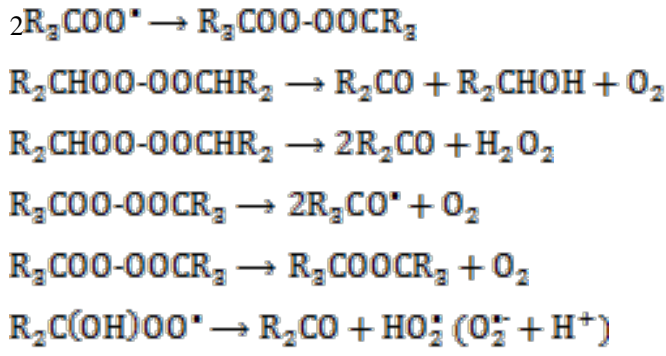

$\mathrm{RCHO} \rightarrow \mathrm{RCH}(\mathrm{OH})_{2} \rightarrow \mathrm{RC}^{*}(\mathrm{OH})_{2} \rightarrow \mathrm{R}(\mathrm{OH})_{2} \mathrm{COO}^{*} \rightarrow \mathrm{RCOOH}$ $\mathrm{RC}(\mathrm{O}) \mathrm{Cl}+\mathrm{H}_{2} \mathrm{O} \rightarrow \mathrm{RCOOH}+\mathrm{HCl}$

$\mathrm{R}_{2} \mathrm{C}^{*}-\mathrm{CClR}_{2}+\mathrm{H}_{2} \mathrm{O} \rightarrow \mathrm{R}_{2} \mathrm{C}^{*}-\mathrm{COHR}_{2}+\mathrm{HCl}$

$\mathrm{RNH}-\mathrm{C}(\mathrm{O}) \mathrm{R}+\mathrm{H}_{2} \mathrm{O} \rightarrow \mathrm{RNH}_{2}+\mathrm{RCOOH}$

$\mathrm{Cl}_{2} \mathrm{C}=\mathrm{O}+\mathrm{H}_{2} \mathrm{O} \rightarrow \mathrm{CO}_{2}+\mathrm{H}^{+}+2 \mathrm{Cl}^{-}$

$\mathrm{HC} \equiv \mathrm{CCl}+\mathrm{H}_{2} \mathrm{O}^{+} \rightarrow \mathrm{CH}_{a}-\mathrm{C}(\mathrm{O}) \mathrm{Cl}$

$\mathrm{ClC} \equiv \mathrm{CCl}+\mathrm{H}_{2} \mathrm{O} \rightarrow \mathrm{ClCH}_{2}-\mathrm{C}(\mathrm{O}) \mathrm{Cl}$

$\mathrm{R}_{2} \mathrm{C}(\mathrm{OH}) \mathrm{Cl} \rightarrow \mathrm{R}_{2} \mathrm{CO}+\mathrm{HCl}$

$\mathrm{R}^{*}(\mathrm{OH}) \mathrm{Cl} \rightarrow \mathrm{ROH}+\mathrm{Cl}^{*}$

$\mathrm{OHC}-\mathrm{COOH}+\mathrm{H}_{2} \mathrm{O}_{2} \rightarrow \mathrm{HO}-\mathrm{O}-\mathrm{CH}(\mathrm{OH})-\mathrm{COOH}$ $\rightarrow \mathrm{HCOOH}+\mathrm{H}_{2} \mathrm{O}+\mathrm{CO}_{2}$

${ }^{a}$ : Peroxyl radicals can decay either bimolecularly or unimolecularly. Bimolecularly decay and $\mathrm{HO}_{2}^{*} / \mathrm{O}_{2}^{*-}$ Elimination are the main reactions of peroxyl radicals. Other reaction such as electron transfer, $\mathrm{H}$ abstraction and double bond addition are ignored because of their insignificance in AOP system [28,29]; ${ }^{b}$ : Because of the polarity of the water molecule, $\beta$-scission and the 1,2-H Shift of oxyl radicals are accelerated significantly. They almost completely exclude other mechanisms such as $\mathrm{H}$ abstraction, disproportionation, and recombination. The latter three mechanisms are typical in either organic solutions or the gas phase but not important in the aqueous phase [18,30]; ${ }^{c}$ : Hydrolysis of aldehydes starts from the formation of hydrated molecules $(4,13,31)$. The hydrogen atom attached to the carbon atom carrying the hydroxyl functional group can then be abstracted, and the resultant carbon-centered radical reacts with $\mathrm{O}_{2}$ to form a peroxyl radical. The peroxyl radical then decomposes into a carboxyl group; ${ }^{d}$ : According to Ellington's study, the half life of amide in environment is about $336 \mathrm{~d} \sim$ centuries. For hydrolysis of amide, $\mathrm{RN}^{+} \mathrm{H}_{2}-\mathrm{C}(\mathrm{OH})\left(\mathrm{O}^{-}\right) \mathrm{R} / \mathrm{RNH}-\mathrm{C}(\mathrm{OH})\left({ }^{+} \mathrm{OH}_{2}\right) \mathrm{R}$ are formed before breakdown to carboxylic acid and amine. And its reversal to reactants is faster than its breakdown [26]. However, in the presence of hydroxyl radicals, the intermediates may react with the radicals to fasten its breakdown to carboxylic acid and amine. 
As shown in the four rows of the table, the formula of " $\mathrm{O}_{2}$ addition" reaction:

$$
\mathrm{R}_{3} \mathrm{C}^{*}+\mathrm{O}_{2} \rightarrow \mathrm{R}_{3} \mathrm{COO}^{*}
$$

is decomposed into four operations. The first operation, as listed in the first row in the table, manipulates the bond of the reactant(s) with index marked by the "AtomSource" columns. A value equal to 1 means there would be bond change on the first reactant (i.e. $\mathrm{R}_{3} \mathrm{C}^{*}$ ), and similarly value of 2 means the bond change would be on the second reactant $\left(\mathrm{O}_{2}\right)$. In this specific case, the bond change was taken place on two atoms of the same reactant $\left(\mathrm{O}_{2}\right)$, thus the "AtomSource1st" is equal to "AtomSource2nd". The indices of the two atoms involved in bond change are listed in "AtomIndex1st" and "AtomInde x 2nd" columns. The value of them in the first row are 0 and 1 , indicate that the bond between the $0_{\text {th }}$ atom in $\mathrm{O}_{2}(\mathrm{O})$ and the $1_{\text {st }}$ atom in $\mathrm{O}_{2}$ (also $\mathrm{O}$ ) would be changed, by the value (-1) in "Bond change" column. Thus the double bond in $\mathrm{O}_{2}$ will be reduced to single bond, after the operation defined in the first row. Similarly, there would be a new bond established between $\mathrm{O}_{2}$ and $\mathrm{R}_{3} \mathrm{C}^{*}$ as defined in the second row. The two "AtomSource" columns are different in the second row, indicating that both of the reactant would be involved in the bond change, as the bond between their $0_{\text {th }}$ atom (the value in "AtomIndex" are both 0) would be increased by 1. The operation in the third row does not involve any bond change, so the value in the "Bond change" column is 0 , and consequentially the "ReactionType" would be set to indicate the type of special operation to be performed on the atoms. In this case, the "Reaction type" is "RemoveRadical", which would remove the radical electron from the $0_{\text {th }}$ atom in the first reactant $\left(\mathrm{R}_{3} \mathrm{C}^{\circ}\right)$. Similarly, the operation in the fourth row would add one radical electron to the $1_{\text {st }}$ atom in the second reactant $\left(\mathrm{O}_{2}\right)$, as the "Reaction type" is "AddRadcial". In these later two cases, the "AtomIndex2nd" and "AtomSource2nd" columns are unused, since there is only one reactant involved in the "RemoveRadical" and "AddRadical" operations.

In this step, the reactants are real chemicals or intermediate products, rather than the patterns of functional groups in the abstracted reactions in section 2.2. The exact location of the operation is determined by the mapping of the chemical to the sub-pattern of the reaction rule. This ensures the definition of each reaction rule could be applied to all chemicals that could have one or more matching to the sub-pattern in that reaction rule, regardless of their complete chemical structures. All illustration of the process is given in the example below.

\subsection{Running Example: “ $\mathrm{O}_{2}$ Addition” Reaction of Radical Trichloroethylene}

Trichloroethylene (TCE) is a chemical compound that has been identified by EPA of proposing acute and chronic health risk to human exposure. Abstracting of a chlorine radical from TCE generates a carbon centered radical:

$\mathrm{O}_{2}$ is abundant in the water and is a default reactant in the reaction system. After transforming the carbon centered radical and $\mathrm{O}_{2}$ into their canonical forms (reordering of atoms), the first step of reaction modeling will go through the chemicals and identify all the possible reactions these chemicals can take. The carbon centered radical can only match with the " $\mathrm{O}_{2}$ addition" reaction rule, while $\mathrm{O}_{2}$ will also match with the " $\mathrm{O}_{2}$ addition" reaction rule. The sub-graph of the first reactant is [C] i.e. carbon with one radical electron and the matching result is the carbon with index of 2 . The sub-graph of the second reactant is $\mathrm{O}=\mathrm{O}$, and both of the atoms (with indices 5 and 6) of oxygen molecule are mapped, as highlighted below:

With the sub-graph mapping result, the reaction execution modeling could execute this reaction according to the operations defined in Table 2, which includes two bond change and a radical electron transfer. In the first step, according to the first row of the table, the bond order will be decreased by one between the atoms indexed by 0 and 1 in the second sub-graph. According to the sub-graph mapping result, the bond change will happen between atom 5 and 6, in the oxygen molecule in Figure 3 , because the mapping of the second sub-graph is $\left(\mathrm{O}_{0} \rightarrow \mathrm{O}_{5}, \mathrm{O}_{1} \rightarrow \mathrm{O}_{6}\right)$. Similarly, the bond order will be increased by one between atom 2 in radical trichloroethylene and atom 5 in oxygen molecule, because the mapping of the first sub-graph is $\left(\mathrm{C}_{0} \rightarrow \mathrm{C}_{2}\right)$ and the second sub-graph is $\left(\mathrm{O}_{0} \rightarrow \mathrm{O}_{5}, \mathrm{O}_{1} \rightarrow \mathrm{O}_{6}\right)$. In the third row of the table the "RemoveRadical" operation would be applied on the first reactant, on atom with index 0 . Thus according to the mapping, the atom 2 of radical trichloroethylene will lose its radical electron. In the last step, the atom 6 of the oxygen molecule will gain a radical electron. The final result is shown below:

Table 1. Reaction execution table for " $\mathrm{O}_{2}$ addition".

\begin{tabular}{cccccc}
\hline Bond change & AtomIndex1st & AtomSource1st & AtomIndex2nd & AtomSource2nd & Reaction type \\
\hline-1 & 0 & 2 & 1 & 2 & N/A \\
1 & 0 & 1 & 0 & 2 & N/A \\
0 & 0 & 1 & 0 & 1 & RemoveRadical \\
0 & 1 & 2 & 1 & 2 & AddRadical \\
\hline
\end{tabular}




\section{Model Application: Reaction Pathway for Atrazine}

Atrazine (2-chloro-4-ethylamino-6-isopropylamino-1,3,5triazine) is one of the most common herbicides found in groundwater and surface water [31,32]. Figure 5 summarized the current literature reports on the atrzine degradation mechanism in advanced oxidation processes. As shown in dash circles in Figure 5, the structure of atrazine contains three main functional groups attached to the triazine ring: isopropylamino group (a), chloro group (b), and ethylamino group (c). Hydroxyl radical attacks the three functional groups and the unsaturated ring structure to degrade the compound. In the figure, R1, $\mathrm{R} 2$, and R3 denote the molecular structure of atrazine after removing the fuctional group a, b, and c respectively. In the advanced oxidation processes, the oxidation of these groups follows the pathway I, II and III as depicted in Figure 5.

The major final product is ammeline [33-37]. The dealkylation and dechlorination occur as parallel reactions [38].<smiles>CC(Cl)=[C]Cl</smiles>

Figure 2. Molecular structure of dichlorovinyl radical.<smiles>C/C(Cl)=C\Cl</smiles>

Figure 3. Molecular structure of dichlorovinyl radical and $\mathrm{O}_{2}$, with highlighted atoms which are involved in the " $\mathrm{O}_{2}$ addition" reaction.<smiles>[OH2+]OC(Cl)=CCl</smiles>

Figure 4. Molecular structure of product from " $\mathrm{O}_{2}$ addition" reaction.

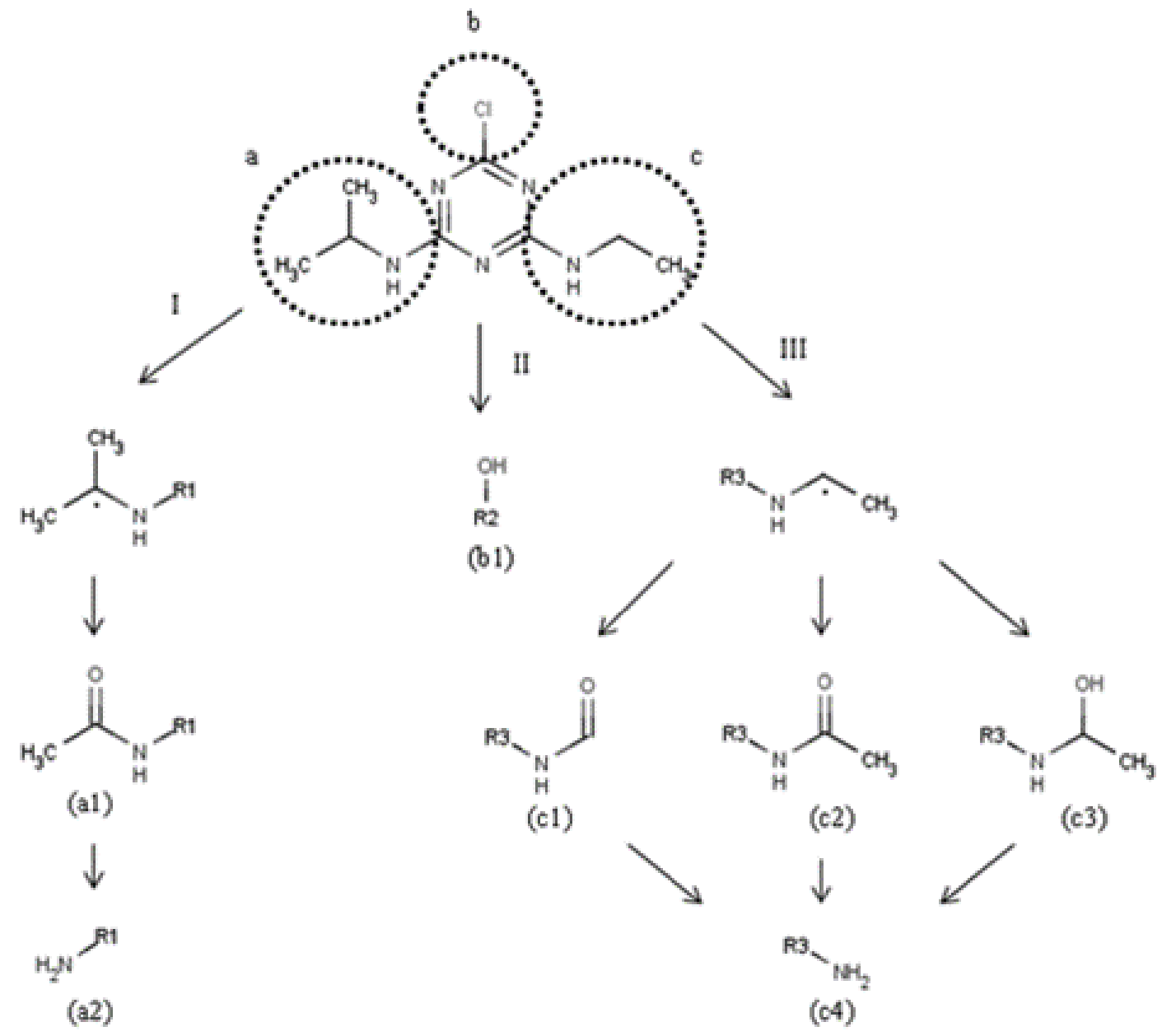

Figure 5. The pathways of atrazine from experiments reported in literatures by functional groups. 
The degradation of isopropylamino group starts from the abstraction of an $\mathrm{H}$ atom by hydroxyl radical. Although all three carbon-hydrogen bonds and the nitrogen-hydrogen bond are possible to be abstracted a hydrogen atom, the reported experiments show that the $\mathrm{H}$-abstraction occurs only on the tertiary carbon. This is due to the fact that $\mathrm{N}$ is more electronegative than $\mathrm{C}$ and the tertiary $\mathrm{C}$ can form a more stable radical structure by $\mathrm{H}$ abstraction than secondary $\mathrm{C}$ and primary $\mathrm{C}$. The pathway generator has priority setting of tertiary $>$ secondary $>$ primary. The generated pathway for this step is as below.

$$
\begin{aligned}
& \mathrm{R1}-\mathrm{NHCH}\left(\mathrm{CH}_{3}\right)_{2}+{ }^{\circ} \mathrm{O} \mathrm{OH} \rightarrow \mathrm{R1}- \\
& \mathrm{NHC}\left(\mathrm{CH}_{3}\right)_{2}+\mathrm{H}_{2} \mathrm{O}
\end{aligned}
$$

The further degradation of the carbon centered radical leads to the acyl species (i.e. a1 in Figure 5) by peroxyl radical mechanisms. [34,41,42]. The pathways generator predicted the formation of acyl species step by step. By $\mathrm{O}_{2}$ addition (reaction 2), the carbon centered radical first formed a peroxyl radical. Two peroxyl radicals can undergo head-to-head recombination to form a tetroxide structure (reaction 3). The decomposition pathway for tetroxide depends on the structure and functional groups of the tetroxide [18]. Due to the unavailability of $\mathrm{H}$ atoms at the $\alpha$-position to the peroxyl function, only one mechanism of bimolecular decay could occur, which lead to an oxyl radical (reaction 4) [18]. The oxyl radicals then underwent $\beta$-scission (reaction 5) to yield acyl species.

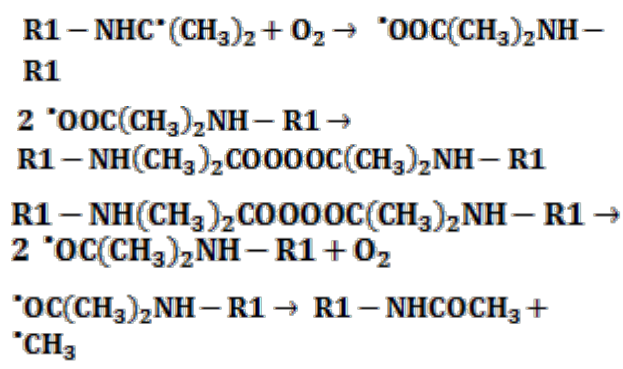

Final product of this pathway is amine group (a2 in Figure 5). It is produced through dealkylation [34,41,42] of the acyl species. This is a water molecule assisted process and is predicted as the hydrolysis of R1- $\mathrm{NHCOCH}_{3}$.

$$
\begin{aligned}
& \text { R1 }-\mathrm{NHCOCH} \\
& \mathrm{CH}_{3} \mathrm{COOH}
\end{aligned}
$$

The pathway of ethylamino group (pathway III) is similar to those of the isopropylamino group (pathway I). First, a carbon centered radical was formed through $\mathrm{H}$ abstraction on the secondary carbon [38-40]. Abstraction from the secondary carbon predominant due to the fact that the resulted carbon centered radical is more stable than that from the primary carbon.

$$
\begin{aligned}
& \mathrm{R} 3-\mathrm{NHCH}_{2} \mathrm{CH}_{3}+{ }^{\circ} \mathrm{OH} \rightarrow \mathrm{R} 3-\mathrm{NHC}^{\cdot} \mathrm{HCH}_{3}+ \\
& \mathrm{H}_{2} \mathrm{O}
\end{aligned}
$$

The carbon centered radical forms peroxyl radical through $\mathrm{O}_{2}$ addition.

$$
\mathrm{R3}-\mathrm{NHC}^{\prime} \mathrm{HCH}_{3}+\mathrm{O}_{2} \rightarrow{ }^{\prime} \mathrm{OOOCHCH} \mathrm{H}_{3} \mathrm{NH}-\mathrm{R3}
$$

The pathway generator has predicted formation of three intermediate groups c1, c2 and c3 (shown in Figure 5) via peroxyl radical mechanisms plus $\beta$-scission of oxyl radicals. These intermediates are consistent with the peroxyl radical mechanisms in the literature [34,41,42].

$$
\begin{aligned}
& 2{ }^{\circ} \mathrm{OOCHCH}_{3} \mathrm{NH}-\mathrm{R3} \rightarrow \\
& \text { R3 - } \mathrm{NHCH}_{3} \mathrm{HCOOOOCHCH}_{3} \mathrm{NH}-\mathrm{R} \\
& \text { R3 }-\mathrm{NHCH}_{3} \mathrm{HCOOOOCHCH} \mathrm{CH}_{3} \mathrm{N3} \rightarrow \mathrm{R3}- \\
& \mathrm{NHCHOHCH}_{3}+\mathrm{R3}-\mathrm{NHCOCH}_{3}+\mathrm{O}_{2} \\
& \text { R3 }-\mathrm{NHCH}_{3} \mathrm{HCOOOOCHCH}_{3} \mathrm{NH}-\mathrm{R3} \rightarrow \\
& 2 \mathrm{R3}-\mathrm{NHCOCH}_{3}+\mathrm{H}_{2} \mathrm{O}_{2} \\
& \text { R3 }-\mathrm{NHCH}_{3} \mathrm{HCOOOOCHCH} \mathrm{CH}_{3} \mathrm{NH}-\mathrm{R3} \rightarrow \\
& 2{ }^{\circ} \mathrm{OCHCH}_{3} \mathrm{NH}-\mathrm{R3}+\mathrm{O}_{2} \\
& { }^{\circ} \mathrm{OCHCH}_{3} \mathrm{NH}-\mathrm{R3} \rightarrow \mathrm{R3}-\mathrm{NHCOH}+{ }^{\circ} \mathrm{CH}_{3}
\end{aligned}
$$

For R3-NHCHOHCH${ }_{3}$ (c3 in Figure 5), it can form R3- $\mathrm{NHCOCH}_{3}$ (c2 in Figure 5) through $\mathrm{H}$ abstraction (reaction 14), $\mathrm{O}_{2}$ addition (reaction 15) and $\mathrm{HO}_{2}{ }^{\circ} / \mathrm{O}_{2}{ }^{-}$ elimination (reaction 16) due to the existence of a hydroxyl group on the $\alpha$ carbon atom.

$$
\begin{aligned}
& \mathrm{R3}-\mathrm{NHCHOHCH}_{3}+{ }^{\circ} \mathrm{OH} \rightarrow \mathbf{R 3}- \\
& \mathrm{NHC}^{\circ} \mathrm{OHCH}_{3}+\mathrm{H}_{2} \\
& \text { R3 }-\mathrm{NHC}^{-} \mathrm{OHCH}_{3}+\mathrm{O}_{2} \rightarrow \text { '0OCOHCH}{ }_{3} \mathrm{NH}- \\
& \text { R3 } \\
& \text { '0OCOHCH}{ }_{3} \mathrm{NH}-\mathrm{R3} \rightarrow \mathrm{R3}-\mathrm{NHCOCH}_{3}+ \\
& \mathrm{HO}_{2}^{*}\left(\mathrm{O}_{2}^{-}+\mathrm{H}^{+}\right)
\end{aligned}
$$

Finally, the three intermediates groups (c1, c2 and c3 in Figure 5) formed amine group (c4)[33,34,41,43]. In the generated pathways, c1, c2 underwent hydrolysis directly, where $\mathrm{c} 3$ has been transformed to c2 in the previous steps (reaction 14-16).

$$
\begin{aligned}
& \mathrm{R3}-\mathrm{NHCOCH} \\
& \mathrm{CH}_{3} \mathrm{COOH}
\end{aligned}
$$

$$
\mathrm{R3}-\mathrm{NHCOH}+\mathrm{H}_{2} \mathrm{O} \rightarrow \mathbf{R 3}-\mathrm{NH}_{2}+\mathrm{HCOOH}
$$

Many reports have described dechlorination (pathway II) as a major pathway of atrazine in the photo-initiated hydroxyl radical processes [34,44,45], and some literature pointed out that the atrazine hydroxylated derivatives are the result of directly photolysis rather than the product of hydroxyl radical processes [37]. However, there are also reports presenting the formation of dechlorinated atrazine in other hydroxyl radical systems, such as Fenton's system [33,35] and ozone/hydrogen peroxide system [39] with small quantities. Although there is no consensus at present, the dechlorination by photolysis has been reported for many chlorinated compounds. In our model, dechlorination is also considered. The dechlorina- 
tion was initiated through a hydroxyl radical attacking the $\mathrm{C}-\mathrm{Cl}$ position of atrazine.

$$
\mathrm{R2}-\mathrm{Cl}+{ }^{\circ} \mathrm{OH} \rightarrow \mathrm{R}^{*}(\mathrm{OH}) \mathrm{Cl} \rightarrow \mathbf{R} 2-\mathrm{OH}+\mathrm{Cl}^{*}
$$

\section{Conclusions}

In this work, an enhanced modeling framework for pathway generation for hydroxyl radical-induced reactions in advanced oxidation process was developed. It is able to enumerate reaction possibilities based on reported elementary reactions for hydroxyl radicals. Competing mechanisms can be selected based on priority settings. The generated reaction pathways for atrazine could be used to explain the formation of experimentally detected byproducts. The model enables alternating and editing reaction rules and their corresponding operations through a graphical user interface to investigate new elementary reactions. The input information is stored as XML databases that are exchangeable between models in different sites. The reactions stored in the model are conceptual, i.e. the reactants are functional groups rather than real chemicals. In the execution of reaction, the functional groups will be mapped back to real chemical to manipulate the bond changes. Thus the whole AOP process can be described in a limited number of reactions.

\section{Acknowledgements}

Funding for this research was provided by the U.S. NSF grant 0854416. Any opinions, findings, conclusions, or recommendations expressed in this paper are those of the authors and do not necessarily reflect the view of the supporting organizations.

\section{REFERENCES}

[1] Glaze, W.H., J.-W. Kang, and D.H. Chapin, The Chemistry of Water Treatment Processes Involving Ozone, Hydrogen Peroxide and Ultraviolet Radiation. Ozone: Science \& Engineering, 1987. 9(4): p. 335-352.

[2] Rosenfeldt, E.J. and K.G. Linden, Degradation of Endocrine Disrupting Chemicals Bisphenol A, Ethinyl Estradiol, and Estradiol during UV Photolysis and Advanced Oxidation Processes. Environmental Science \& Technology, 2004. 38(20): p. 5476-5483.

[3] Huber, M.M., et al., Oxidation of Pharmaceuticals during Ozonation and Advanced Oxidation Processes. Environmental Science \& Technology, 2003. 37(5): p. 1016-1024.

[4] Li, K. and J. Crittenden, Computerized Pathway Elucidation for Hydroxyl Radical-Induced Chain Reaction Mechanisms in Aqueous Phase Advanced Oxidation Processes. Environmental Science \& Technology, 2009. 43(8): p. 2831-2837.

[5] Temkin, O.N., A.V. Zeigarnik, and D.G. Bonchev,
Chemical Reaction Networks: A Graph-Theoretical Approach. Book, 1996.

[6] Hendrickson, J.B., Descriptions of reactions: Their logic and applications. Recueil des Travaux Chimiques des Pays-Bas, 1992. 111(6): p. 323-334.

[7] Abe, H., et al., A convenient notation system for organic structure on the basis of connectivity stack. Journal of Chemical Information and Computer Sciences, 1984. 24(4): p. 212-216.

[8] Weininger, D., SMILES, a chemical language and information system. 1. introduction to methodology and encoding rules. J. Chem. Inf. Comput. Sci., 1988. 28(1): p. 31-36.

[9] Homer, R.W., et al., SYBYL Line Notation (SLN): A Single Notation To Represent Chemical Structures, Queries, Reactions, and Virtual Libraries. Journal of Chemical Information and Modeling, 2008. 48(12): p. 2294-2307.

[10] Weininger, D., A. Weininger, and J.L. Weininger, SMILES. 2. Algorithm for generation of unique SMILES notation. Journal of Chemical Information and Computer Sciences, 1989. 29(2): p. 97-101.

[11] LLC, G.S.S., Indigo. Web.

[12] Asmus, K.D., H. Moeckel, and A. Henglein, Pulse radiolytic study of the site of hydroxyl radical attack on aliphatic alcohols in aqueous solution. The Journal of Physical Chemistry, 1973. 77(10): p. 1218-1221.

[13] Schuchmann, M.N. and C. Von Sonntag, Hydroxyl radical-induced oxidation of diethyl ether in oxygenated aqueous solution. A product and pulse radiolysis study. The Journal of Physical Chemistry, 1982. 86(11): p. 1995-2000.

[14] Ulanski, P., et al., Hydroxyl-radical-induced reactions of poly (acrylic acid); a pulse radiolysis, EPR and product study. Part II. Oxygenated aqueous solutions. Journal of the Chemical Society, Perkin Transactions 2, 1996(1): p. 23-28.

[15] Pryor, W.A., Free Radicals1966, New York: McGraw-Hill Book Company.

[16] Huyser, E.S., Free-Radical Chain Reactions1970, New York: Johns Wiley \& Sons, Inc.

[17] Alfassi, Z.B., ed. General Aspects of the Chemistry of Radicals. 1999, Wiley: Chichester, UK.

[18] von Sonntag, C.a.H.-P.S., Peroxyl Radicals in Aqueous Solutions, in Peroxyl Radicals, Z.B. Alfassi, Editor 1997, John Wiley \& Sons: New York. p. 172-234.

[19] Ilan, Y., J. Rabani, and A. Henglein, Pulse radiolytic investigations of peroxy radicals produced from 2-propanol and methanol. The Journal of Physical Chemistry, 1976. 80(14): p. 1558-1562.

[20] Gilbert, B.C., R. G. G. Holmes and R. O. C. Norman, Electron spin resonance studies. Part LII. Reactions of secondary alkoxyl radicals. J. Chem. Res., Synopses, 1977(1): p. 1.

[21] Schuchmann, H.-P. and C. von Sonntag, Photolysis at 185 $\mathrm{nm}$ of dimethyl ether in aqueous solution: involvement of the hydroxymethyl radical. Journal of Photochemistry, 
1981. 16(4): p. 289-295.

[22] Stefan, M.I. and J.R. Bolton, Mechanism of the Degradation of 1,4-Dioxane in Dilute Aqueous Solution Using the UV/Hydrogen Peroxide Process. Environmental Science \& Technology, 1998. 32(11): p. 1588-1595.

[23] Vel Leitner, N.K., P. Berger, and B. Legube, Oxidation of Amino Groups by Hydroxyl Radicals in Relation to the Oxidation Degree of the $\alpha$-Carbon. Environmental Science \& Technology, 2002. 36(14): p. 3083-3089.

[24] Stefan, M.I., A.R. Hoy, and J.R. Bolton, Kinetics and Mechanism of the Degradation and Mineralization of Acetone in Dilute Aqueous Solution Sensitized by the UV Photolysis of Hydrogen Peroxide. Environmental Science \& Technology, 1996. 30(7): p. 2382-2390.

[25] Koltzenburg, G., G. Behrens, and D. Schulte-Frohlinde, Fast hydrolysis of alkyl radicals with leaving groups in the $\beta$ position. Journal of the American Chemical Society, 1982. 104(25): p. 7311-7312.

[26] Richard A. Larson, E.J.W., Reaction Mechanisms in Environmental Organic Chemistry1994: CRC Press.

[27] Getoff, N., Peroxyl radicals in the treatment of waste solutions, in Peroxyl Radical, Z.B. Alfassi, Editor 1997, John Wiley \& Sons: New York.

[28] Merenyi, G., J. Lind, and L. Engman, One- and two-electron reduction potentials of peroxyl radicals and related species. Journal of the Chemical Society, Perkin Transactions 2, 1994(12): p. 2551-2553.

[29] Schuchmann, M.N. and C. von Sonntag, Hydroxyl radical induced oxidation of diethyl ether in oxygenated aqueous solution. A product and pulse radiolysis study. [Gamma radiation]. Journal Name: J. Phys. Chem.; (United States); Journal Volume: 86:11, 1982: p. Medium: X; Size: Pages: 1995-2000.

[30] Schuchmann, M.N., H. Zegota and C. v. Sonntag, Acetate Peroxyl Radicals, *O2CHCO2-: A Study on the r-Radiolysis and Pulse Radiolysis of Acetate in Oxygenated Aqueous Solutions. Z. Naturforsch, 1985(40B): p. 215.

[31] McMurray, T.A., P.S.M. Dunlop, and J.A. Byrne, The photocatalytic degradation of atrazine on nanoparticulate TiO2 films. Journal of Photochemistry and Photobiology A: Chemistry, 2006. 182(1): p. 43-51.

[32] Ou, X., et al., Atrazine Photodegradation in Aqueous Solution Induced by Interaction of Humic Acids and Iron: Photoformation of Iron(II) and Hydrogen Peroxide. Journal of Agricultural and Food Chemistry, 2007. 55(21): p. 8650-8656.

[33] Chan, K.H. and W. Chu, Model applications and mechanism study on the degradation of atrazine by Fenton's system. Journal of Hazardous Materials, 2005. 118(1-3): p. 227-237.
[34] Chan, K.-H. and W. Chu, Model Applications and Intermediates Quantification of Atrazine Degradation by UV-Enhanced Fenton Process. Journal of Agricultural and Food Chemistry, 2006. 54(5): p. 1804-1813.

[35] Arnold, S.M., W.J. Hickey, and R.F. Harris, Degradation of Atrazine by Fenton's Reagent: Condition Optimization and Product Quantification. Environmental Science \& Technology, 1995. 29(8): p. 2083-2089.

[36] Nélieu, S., L. Kerhoas, and J. Einhorn, Degradation of Atrazine into Ammeline by Combined Ozone/Hydrogen Peroxide Treatment in Water. Environmental Science \& Technology, 1999. 34(3): p. 430-437.

[37] Torrents, A., et al., Atrazine photolysis: Mechanistic investigations of direct and nitrate mediated hydroxy radical processes and the influence of dissolved organic carbon from the Chesapeake Bay. Environmental Science \& Technology, 1997. 31(5): p. 1476-1482.

[38] Balci, B., et al., Degradation of atrazine in aqueous medium by electrocatalytically generated hydroxyl radicals. A kinetic and mechanistic study. Water Research, 2009. 43(7): p. 1924-1934.

[39] Acero, J.L., K. Stemmler, and U. von Gunten, Degradation Kinetics of Atrazine and Its Degradation Products with Ozone and $\mathrm{OH}$ Radicals: A Predictive Tool for Drinking Water Treatment. Environmental Science \& Technology, 2000. 34(4): p. 591-597.

[40] Bianchi, C.L., et al., Mechanism and efficiency of atrazine degradation under combined oxidation processes. Applied Catalysis B: Environmental, 2006. 64(1-2): p. 131-138.

[41] Granados-Oliveros, G., et al., Degradation of atrazine using metalloporphyrins supported on $\mathrm{TiO} 2$ under visible light irradiation. Applied Catalysis B: Environmental, 2009. 89(3-4): p. 448-454.

[42] Mackul'ak, T., J. Prousek, and L.u. Švorc, Degradation of atrazine by Fenton and modified Fenton reactions. Monatshefte für Chemie / Chemical Monthly, 2011. 142(6): p. 561-567.

[43] Rebelo, S.L.H., et al., Catalytic oxidative degradation of s-triazine and phenoxyalkanoic acid based herbicides with metalloporphyrins and hydrogen peroxide: Identification of two distinct reaction schemes. Journal of Molecular Catalysis A: Chemical, 2009. 297(1): p. 35-43.

[44] Hiskia, A., et al., Sonolytic, photolytic, and photocatalytic decomposition of atrazine in the presence of polyoxometalates. Environmental Science \& Technology, 2001. 35(11): p. 2358-2364.

[45] Pelizzetti, E., et al., Photocatalytic degradation of atrazine and other s-triazine herbicides. Environmental Science \& Technology, 1990. 24(10): p. 1559-1565. 